Pesq. Vet. Bras. 36(8):687-693, agosto 2016 DOI: $10.1590 /$ S0100-736X2016000800002

\title{
Alterações bioquímicas, anatômicas e histopatológicas em fígado de Gallus gallus Linnaeus, 1758 experimentalmente infectados por Borrelia anserina Sakharoff, $1891^{1}$
}

\author{
Marcio B. Cepeda ${ }^{2}$, Patricia B. Cepeda², Bruna A. Baêta², Fabrício N. Gaudêncio ${ }^{3}$, \\ Matheus D. Cordeiro ${ }^{2}$, Paulo C. Magalhães-Matos ${ }^{2}$, Marilene F. Brito ${ }^{4}$ \\ e Adivaldo H. Fonseca ${ }^{2 *}$
}

\begin{abstract}
Cepeda M.B., Cepeda P.B., Baêta B.A., Gaudêncio F.N., Cordeiro M.D., Magalhães-Matos P.C., Brito M.F. \& Fonseca A.H. 2016. [Biochemical, anatomical and histopathological changes in the liver of Gallus gallus Linnaeus, 1758 experimentally infected by Borrelia anserine Sakharoff, 1891.] Alterações bioquímicas, anatômicas e histopatológicas em fígado de Gallus gallus Linnaeus, 1758, experimentalmente infectados por Borrelia anserina Sakharoff, 1891. Pesquisa Veterinária Brasileira 36(8):687-693. Departamento de Parasitologia Animal, Instituto de Veterinária, Universidade Federal Rural do Rio de Janeiro, BR-465 Km 7, Seropédica, RJ 23890-000, Brazil. E-mail: adivaldofonseca@yahoo.com

Spirochetosis avian is a septicemic disease of acute course and cosmopolitan can affect various avian species, caused by Borrelia anserina and transmitted by Argas miniatus. The experiment aimed to evaluate the biochemical, anatomical and histopathological changes in the liver of Gallus gallus caused by experimental infection with B. anserina. A total of 40 fowls of the species G. gallus were divided into four randomized groups of ten fowls each: G1 - inoculated with serum infected with B. anserina; G2 - inoculated with $0.9 \%$ saline; G3 - exposed to nymphs of 3rd instar of $A$. miniatus infected with B. anserina; G4 - exposed to ticks nymphs of 3rd instar of $A$. miniatus free of $B$. anserina. The fowls of Groups 1 and 3 expressed at 3 and 6 days post-inoculation (DAI) respectively, symptoms characteristic of the disease as lack of appetite, weight loss, drowsiness, greenish diarrhea, pale mucous membranes , ruffled feathers and hyperthermia. ALT of group 1 levels were significantly higher only at the $12^{\circ}$ and $24^{\circ}$ day after inoculation (DAI) compared with its control group (group 2), and in group 3 these levels remained high until the $20^{\circ}$ DAI as compared with its control group (group 4). AST enzyme fluctuated little in the experimental groups, although elevations at $12^{\circ}$ DAI has been found in group 1 and 3. The liver of fowls in groups 1 and 3, presented at necropsy moderate hepatomegaly, congestion, irregular surface and red color to cyanotic. If found even small whitish spots on the surface. The histopathology revealed congestion, mononuclear inflammatory infiltrates, fibrinoid necrotic foci, dilatation of sinusoids, and vacuolation of hepatocytes. The Warthin-Starry staining revealed in the liver of fowls in groups 1 and 3 the presence of spirochetes compatible with B. anserina, often within blood vessels.

INDEX TERMS: Liver, Gallus gallus, Borrelia anserina, spirochetosis, tick borne diseases, domestic chicken, serum biochemistry, histopathology.
\end{abstract}

\footnotetext{
${ }^{1}$ Recebido em 23 de junho de 2015.

Aceito para publicação em 23 de abril de 2016.

${ }^{2}$ Laboratório de Doenças Parasitárias, Departamento de Epidemiologia e Saúde Pública (DESP), Instituto de Veterinária (IV), Universidade Federal Rural do Rio de Janeiro (UFRRJ), Seropédica, RJ 23890-000, Brasil. *Autor para correspondência: adivaldofonseca@yahoo.com

${ }^{3}$ Laboratório de Biofísica, Instituto de Biologia, UFRRJ, BR-465 Km 47, Seropédica, RJ 23891-000, Brasil.

${ }^{4}$ Setor de Anatomia Patológica, DESP, IV-UFRRJ, Seropédica, RJ 23890000, Brasil
}

RESUMO.- A espiroquetose aviária é uma enfermidade septicêmica de curso agudo, cosmopolita, que acomete diversas espécies aviárias, causada por Borrelia anserina e transmitida pelo carrapato Argas miniatus. 0 experimento teve como objetivos avaliar as alterações bioquímicas e anátomo-histopatológicas no fígado de Gallus gallus, causadas pela infecção experimental por B. anserina. Quarenta aves da espécie G. gallus foram divididas em quatro grupos 
inteiramente casualizados com 10 animais cada: G1 - inoculado com soro infectado com B. anserina; G2 - inoculado com soro fisiológico a 0,9\%; G3 - exposto a ninfas de terceiro ínstar de A. miniatus infectados por B. anserina; G4 - exposto a ninfas de terceiro ínstar de $A$. miniatus livres de $B$. anserina. As aves dos Grupos 1 e 3 manifestaram no 3o e 6음 dias pós-inoculação (DPI) respectivamente, sintomatologia característica da doença como inapetência, perda de peso, sonolência, diarreia esverdeada, mucosas hipocoradas, penas arrepiadas e hipertermia. Os níveis de ALT do Grupo 1 mostraram-se significativamente mais elevados apenas no $12^{\circ}$ DPI e $24^{\circ}$ DPI em relação ao seu grupo controle (Grupo 2) e no Grupo 3 esses níveis se mantiveram elevados até o $20^{\circ}$ DPI em comparação ao seu grupo controle (Grupo 4). Os níveis da enzima AST pouco oscilaram nos grupos experimentais, embora tenham sido encontradas elevações no $12^{\circ}$ DPI nos Grupos 1 e 3. Os fígados das aves dos Grupos 1 e 3 apresentaram à necropsia, moderada hepatomegalia, congestão, superfície irregular e coloração vermelha a cianótica; constataram-se ainda pequenos pontos esbranquiçados na superfície. A histopatologia do fígado revelou congestão, infiltrados inflamatórios mononucleares, focos de necrose fibrinoide, dilatação dos sinusoides e vacuolização de hepatócitos. A coloração de Warthin-Starry revelou, nos fígados das aves dos Grupos 1 e 3, a presença de espiroquetas compatíveis com $B$. anserina, frequentemente no interior de vasos sanguíneos.

TERMOS DE INDEXAÇÃO: Fígado, Gallus gallus, Borrelia anserina, espiroquetose, doenças transmitidas por carrapatos, galinhas domésticas, bioquímica sérica, histopatologia.

\section{INTRODUÇÃO}

A borreliose aviária é considerada uma enfermidade de importância econômica, que atinge principalmente criações de aves onde é forte a inserção do sistema orgânico; essa enfermidade é responsável por altas taxas de mortalidade em aves de criações rústicas, com maior prevalência nas aves jovens (Wouda et al. 1975, Lisbôa et al. 2008). Este tipo de sistema de produção apresenta algumas desvantagens como o baixo investimento em equipamentos e técnicas sanitárias inadequadas, o que facilita a instalação de parasitoses (Cruz et al. 2013).

0 agente etiológico, Borrelia anserina, é o causador da espiroquetose aviária em Gallus gallus Linnaeus, 1758, e foi descrita pela primeira vez na Rússia, na região do Caucasus, por Sakharoff (1891), quando este investigava a causa de septicemia em gansos da espécie Anser cygnoides Linnaeus 1758. No Brasil, a enfermidade foi relatada por Marchoux \& Salimbeni (1903) quando estudavam o curso da infecção natural por B. anserina em galinhas. Esta espiroqueta pode ser encontrada no plasma sanguíneo das aves infectadas durante os estágios iniciais da doença (Dickie \& Barrera 1964, Burgdorfer \& Schwan 1991).

O quadro clínico da enfermidade manifesta-se por hipertermia e polidpsia inicial, fraqueza muscular, sonolência, inapetência, diarreia esverdeada, cianose de mucosas, hipotermia, transtornos paralíticos e até a morte (Boero 1967).
O vetor responsável pela transmissão de $B$. anserina na América do Sul é o carrapato da espécie Argas (Persicargas) miniatus Koch, 1844. Esse argasídeo se mantém na natureza, principalmente, em pequenas criações rústicas e domésticas de G. gallus, e sua importância se deve às perdas na produtividade decorrente do hematofagismo e da transmissão deste agente patogênico pelas vias transestadial e primordialmente transovariana (Hoogstraal 1979, Marchoux \& Salimbeni 1903, Lisbôa 2006).

Variações bioquímicas são comumente utilizadas no auxílio do diagnóstico de diversas doenças em animais domésticos e de produção (Borsa et al. 2006). Dentre as enzimas hepáticas mais utilizadas na rotina laboratorial estão a alanina-aminotransferase (ALT) e aspartato aminotransferase (AST), as quais, quando apresentam atividades elevadas indicam a ocorrência de lesões hepáticas ou musculares nas aves e em outros animais (Kaneko et al. 1997, Jaensch 2000). Alterações na atividade destas enzimas foram relatadas por Vashist (2011) em G. gallus infectados experimentalmente por $B$. anserina.

Inúmeras alterações hepáticas podem ser encontradas no fígado de frangos, e indicam a ocorrência de distúrbios circulatórios, tóxicos, infecciosos e neoplásicos. Algumas lesões hepáticas são inespecíficas quanto à etiologia, mas fornecem informações essenciais sobre a ocorrência de enfermidades sistêmicas (Hoerr 1996). Alterações hepáticas em resposta à borreliose aviária têm sido relatadas em $G$. gallus e incluem diversas alterações observadas quanto à morfologia e funcionalidade do órgão, assim como alterações ao nível celular (Boero 1967, Levaditi \& Lange 1905).

0 objetivo deste estudo foi relatar as alterações bioquímicas no sangue e anátomo-histopatológicas em fígados de G. Gallus em resposta à infecção experimental causada por B. anserina.

\section{MATERIAL E MÉTODOS}

Este estudo foi aprovado pela Comissão de Ética para o Uso de Animais (CEUA/IV/UFRRJ, Protocolo 123/2014).

Quarenta aves com 1 dia de vida, vacinadas para Doença de Marek e Bouba Aviária, de mesmo lote e linhagem comercial "Redbro Plumé”, oriundas de um núcleo avícola localizado no município de Caxias do Sul, RS foram utilizadas. As aves foram mantidas em um manejo que proporcionava o máximo de conforto e bem-estar, seguindo rigorosamente o Manual Técnico de Cuidados Iniciais na Produção do Frango de Corte Colonial (Avila 2004), com espaço, temperatura e ventilação adequados para cada fase de criação e fornecimento diário de água e ração.

No dia anterior ao início do experimento foram realizados esfregaços sanguíneos que foram corados pelo Giemsa; todas as aves se apresentaram negativas para hemoparasitos.

Aos 49 dias de idade as aves foram divididas em quatro grupos inteiramente casualizados, com 10 animais em cada grupo, e alojadas em gaiolas suspensas, ficando duas por gaiola. As aves foram identificadas por meio de anilhas de plástico em uma das patas, marcadas com o número do animal. 0 Grupo 1 foi constituído de aves inoculadas por via intramuscular com soro positivo para B. anserina, com duas passagens sanguíneas prévias em aves saudáveis e o Grupo 2, aves inoculadas por via intramuscular com solução fisiológica a 0,9\%. Cada ave do Grupo 1 recebeu o inóculo de $250 \mu \mathrm{L}$ de soro infectado, com uma concentração de $3,7 \times 10^{6}$ espiroquetas/ml. Em cada ave do Grupo 2, foram administrados, 
via intramuscular, $250 \mu \mathrm{L}$ de soro fisiológico a 0,9\%. 0 Grupo 3 foi infestado com 4 ninfas de terceiro ínstar de Argas miniatus infectadas por Borrelia anserina, enquanto que o Grupo 4 foi infestado por meio de 4 ninfas de terceiro ínstar de $A$. miniatus livres de $B$. anserina (Lisbôa 2006).

Para a obtenção de soro e carrapatos positivos para B. anserina utilizados na infecção dos Grupos 1 e 3, respectivamente, uma ave adulta livre de hemoparasitos foi imunossuprimida com acetato de metilprednisolona (Depo-Medrol ${ }^{\circledR}$ ) (Souza 1998), administrado por via intramuscular, em dose única de $30 \mathrm{mg} / \mathrm{Kg}$. No dia seguinte a ave recebeu o inóculo de 0,5ml (Lisbôa et al. 2009) de soro infectado com $B$. anserina já submetido a uma passagem previamente criopreservado em dimetil-sulfóxido (DMSO) a $10 \%$ (Labruna et al. 1999). No quarto dia pós-inoculação (DPI), quando a ave apresentava pico de parasitemia, confirmado pela presença de inúmeras espiroquetas através da visualização do sangue em microscopia de campo escuro, foram coletadas amostras de soro infectado para o Grupo 1 e ninfas de segundo ínstar foram alimentadas até completo ingurgitamento para a obtenção de carrapatos infectados utilizados no Grupo 3. Após a ecdise dessas ninfas, cada ave do Grupo 3 foi infestada com quatro carrapatos infectados.

Os Grupos 2 e 4 foram utilizados como controles internos para os Grupos 1 e 3 submetidos à infecção, funcionando como meios de comparação aos parâmetros normais. Sendo assim, todos os grupos foram submetidos às mesmas condições experimentais.

Amostras de sangue total das aves dos quatro grupos experimentais foram coletadas três dias antes do início da infecção, aos 46 dias de vida, e depois no $4^{\circ}, 8^{\circ}, 12^{\circ}, 16^{\circ}, 20^{\circ}$ e $24^{\circ}$ DPI. As amostras de sangue foram centrifugadas e os soros obtidos foram conservados em freezer a $-80^{\circ} \mathrm{C}$, sendo processados no Laboratório de Quimioterapia Experimental em Parasitologia Veterinária (LQEPV/ UFRRJ) e submetidos à análise da bioquímica sérica. Foram avaliadas, durante o curso da infecção as atividades enzimáticas de aspartato aminotransferase (AST) e alanina aminotransferase (ALT).

Para proceder à análise das amostras de soro, foi utilizado o analisador A15 automatizado (Applied Biosystems). As análises foram feitas pelo método colorimétrico, através de "kits" comerciais (Biosystems Reagents e Instruments).

Para avaliar a atividade enzimática de ALT, $25 \mu \mathrm{L}$ foram adicionados a $300 \mu \mathrm{L}$ do reagente $(150 \mathrm{mmol} / \mathrm{L}$ Tris, $750 \mathrm{mmol} / \mathrm{L}$ de L - Alanina, Desidrogenase láctica >1350 U/L, pH 7.3, 1,3mmol/L $\mathrm{NADH}, 75 \mathrm{mmol} / \mathrm{L}$ de 2 - oxoglutarato, 148mmol/L de hidróxido de sódio, 9,5g/L de azida de sódio) sendo que o produto formado foi determinado por espectofotometria de absorção máxima a $340 \mathrm{~nm}$. As leituras foram expressas em U/L. Para a determinação da atividade enzimática de AST, $25 \mu \mathrm{L}$ de soro foram adicionados a $300 \mu \mathrm{L}$ de reagente $(121 \mathrm{mmol} / \mathrm{L}$ de Tris, $362 \mathrm{mmol} / \mathrm{L}$ de L-aspartato, Desidrogenase maláctica $>460 \mathrm{U} / \mathrm{L}$, Desidrogenase láctica > $660 \mathrm{U} / \mathrm{L}$ de, $\mathrm{pH} 7.8,1,3 \mathrm{mmol} / \mathrm{L}$ de NADH, 75mmol/L de 2-oxoglutarato, $255 \mathrm{mmol} / \mathrm{L}$ de hidróxido de sódio, 9,5g de azida de sódio), sendo formado um produto por espectofotometria de absorção máxima de 340 nm. As leituras foram expressas em U/L.

Duas aves do Grupo 1 e duas do Grupo 2, foram eutanasiadas no quarto DPI, período no qual ocorre o pico de parasitemia nas aves infectadas pelo soro (Grupo 1), de acordo com Nasri et al. (2010). Duas aves do Grupo 3 e duas do Grupo 4, foram eutanasiadas no oitavo DPI, período em que ocorre o pico de parasitemia do Grupo 3 pela alimentação de carrapatos infectados (Hutyra et al. 1947, McNeil et al. 1949, Boero 1967, Bier 1985).

As aves foram eutanasiadas conforme os métodos recomendados nas Diretrizes da Prática de Eutanásia do CONCEA para aves (Brasil 2013). Para a realização da eutanásia, foi administrado, por via endovenosa, $1 \mathrm{~mL} / \mathrm{kg}$ de tiopental sódico (Thiopentax ${ }^{\circledR}$ ). As aves foram auscultadas durante o procedimento para comprovar a ausência do batimento cardíaco e a eficiência da práti- ca. A necropsia das aves e a coleta de material foram realizadas de acordo com o Manual de Necropsia do Centro de Diagnóstico e Pesquisa em Patologia Aviária da Universidade Federal do Rio Grande do Sul (CDPA 2014).

Fragmentos de fígado das aves infectadas foram coletados, fixados em formol a 10\% tamponado, processados pelos métodos usuais para histopatologia, cortados em micrótomo à espessura de $5 \mu \mathrm{m}$ e corados pela Hematoxilina-Eosina (HE) e pelo Warthin-Starry. As alterações histológicas foram observadas em microscópio HUND WETZALAR H600 e as imagens capturadas pela câmera digital NIKON COOLPIX 4300. Os procedimentos histológicos foram realizados no Setor de Anatomia Patológica da Universidade Federal Rural do Rio de Janeiro.

Os gráficos foram plotados no Microsoft Excel 2007. A análise quantitativa dos parâmetros bioquímicos estudados foi realizada através do programa estatístico Statgraphics Centurion XVI - Version 16.2.04 (64-bit), e os dados foram analisados de forma independente para cada grupo experimental em cada dia de infecção.

\section{RESULTADOS}

Todas as aves dos Grupos 1 e 3 manifestaram, a partir do 3 o DPI e 6DPI respectivamente, sintomatologia caracterizada por inapetência, perda de peso, sonolência, diarreia esverdeada, mucosas hipocoradas, penas arrepiadas e hipertermia. Os sinais clínicos perduraram até o 9ํDPI; após este período não mais foram observadas espiroquetas no sangue periférico, o que resultou no início de uma melhora no quadro clínico das aves. Os resultados dos valores bioquímicos das aves do Grupo 1 correspondentes a ALT, apresentaram elevação em sua atividade apenas no $12^{\circ}$ e $24^{\circ}$ DPI, sendo estes os maiores valores séricos para esta enzima no grupo. Após o pico enzimático no $12^{\circ} \mathrm{DPI}$, houve uma normalização do seu nível, aproximando-se dos níveis do seu grupo controle (Grupo 2). Quanto ao grupo exposto aos carrapatos infectados (Grupo 3), os níveis de ALT se mantiveram mais elevados que os do seu grupo controle (Grupo 4) até o 20을 (Fig.1). Os níveis séricos de AST do Grupo 1 estiveram próximos aos do grupo controle, sendo observadas pequenas oscilações de sua atividade exceto no $12^{\circ}$ DPI, o qual apresentou um aumento considerável para esta enzima. No Grupo 3 houve um pequeno aumento entre $8^{\circ}$ e $12^{\circ}$ DPI e uma queda após esse período, com posterior normalização (Fig.2).

Os fígados das aves dos Grupos 1 e 3 apresentaram, à necropsia, moderada hepatomegalia, congestão, superfície irregular e coloração vermelha a cianótica. Constataram-se ainda pequenos pontos esbranquiçados na superfície (Fig.3 e 4). A histopatologia revelou congestão, infiltrados inflamatórios mononucleares, focos de necrose fibrinoide, dilatação dos sinusoides e vacuolização de hepatócitos.

0 fígado das aves do Grupo 1 ocupou grande parte da cavidade celomática, quando inspecionado ainda na carcaça e os fígados das aves do Grupo 3 se mostraram friáveis após a manipulação. As vesículas biliares das aves dos dois grupos estavam repletas, com bile espessa, escura e grumosa.

A análise microscópica dos fígados das aves do Grupo 1 revelou discreta vacuolização difusa nos hepatócitos, pequenos focos de infiltrado inflamatório mononuclear predominantemente perivascular, rico em macrófagos (Fig.5) que variaram de leves a moderados, e pericolangite com 

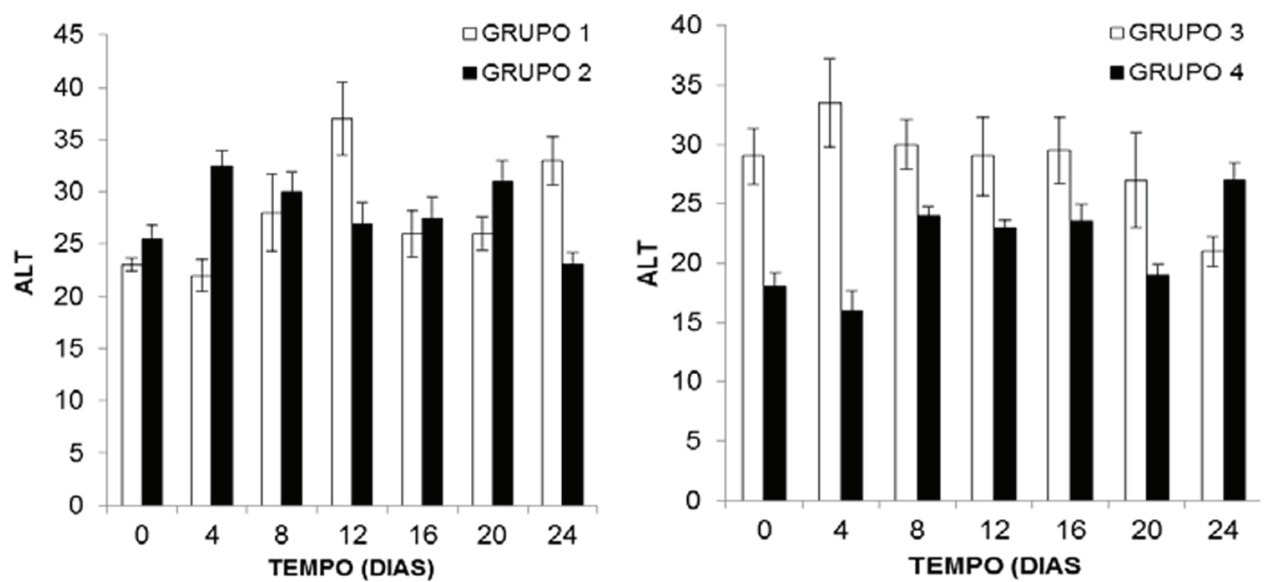

Fig.1. Atividade da alanina transaminase (ALT) nos quatro grupos experimentais. Grupo 1 = Aves inoculadas com soro infectado por Borrelia anserina. Grupo 2 = Aves inoculadas com soro fisiológico a 0,9\%. Grupo $3=$ Aves expostas a carrapatos infectados com Borrelia anserina. Grupo 4 = Aves expostas a carrapatos livres de Borrelia anserina.
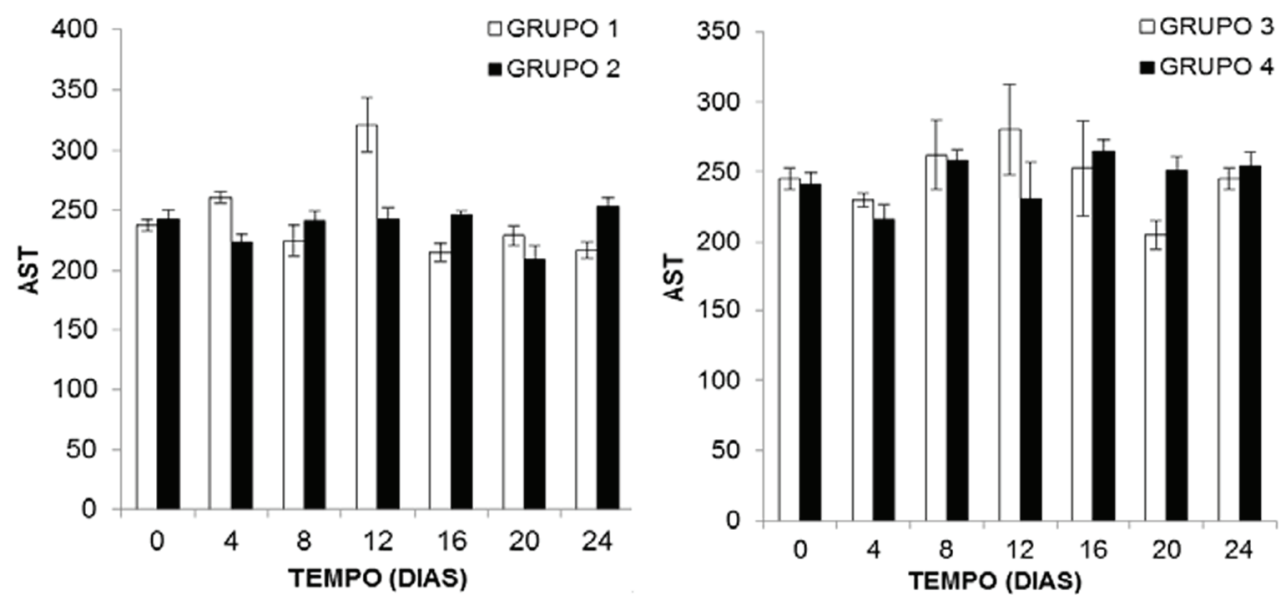

Fig.2. Atividade da aspartato aminotransferase (AST) nos quatro grupos experimentais. Grupo 1 = Aves inoculadas com soro infectado por Borrelia anserina. Grupo 2 = Aves inoculadas com soro fisiológico a 0,9\%. Grupo 3 = Aves expostas a carrapatos infectados com Borrelia anserina. Grupo 4 = Aves expostas a carrapatos livres de Borrelia anserina.

presença de eosinófilos, além de sinusoides hepáticos dilatados e congestos, discreta bilestase, edema dos espaços de Disse e focos de necrose fibrinoide (Fig.8). No fígado das aves do Grupo 3 foram observados acentuados focos de infiltrado inflamatório mononuclear perivascular e periportal, rico em macrófagos e eosinófilos (Fig.6-7). Havia ainda dilatação dos sinusoides e trombos de fibrina no interior dos vasos.

A coloração de Warthin-Starry revelou, nos fígados das aves dos Grupos 1 e 3, a presença de espiroquetas compatíveis com B. anserina, frequentemente no interior de vasos sanguíneos (Fig.9 e10).

\section{DISCUSSÃO}

Os sinais clínicos observados nos Grupos 1 e 3 foram mais intensos na primeira e segunda semanas após a infecção, respectivamente. Estudos anteriores envolvendo galinhas domésticas infectadas por Borellia anserina, demonstraram aves com quadro clínico característico da infecção como anorexia, diarreia esverdeada, palidez de mucosas, paralisia de asas, penas arrepiadas e hipertermia (Lisbôa 2006, Nasri et al. 2010). Sintomatologia semelhante foi ob- servada neste estudo, apresentando-se durante todo o curso da infecção como uma doença de caráter agudo.

As alterações encontradas nos valores de ALT na segunda semana pós-inoculação diferem dos resultados encontrados por Vashist (2011), que estudando as alterações bioquímicas causadas pela infecção, encontrou níveis elevados da enzima na terceira semana de infecção, após inocular soro infectado com B. anserina em galinhas domésticas. A elevação enzimática de ALT observada no grupo controle (Grupo 2) durante os primeiros dias de avaliação, pode ter ocorrido devido ao estresse mediante a contenção para coleta e/ou variações ambientais, que por muitas vezes alteram a fisiologia e o metabolismo normais dos animais. Vashist (2011) relatou aumento das atividades enzimáticas de ALT na primeira semana pós-inoculação de B. anserina. Este aumento da atividade inicial foi explicado por Borsa et al. (2006), quando relaciona o clima, manejo e tipo de alimentação com possíveis interferências no resultado das análises bioquímicas. No presente estudo, foi observada uma pequena elevação da atividade enzimática de AST no quarto DPI do Grupo 1, com maiores valores no $12^{\circ}$ DPI, enquanto Rivetz et al. (1977) observaram elevação signi- 


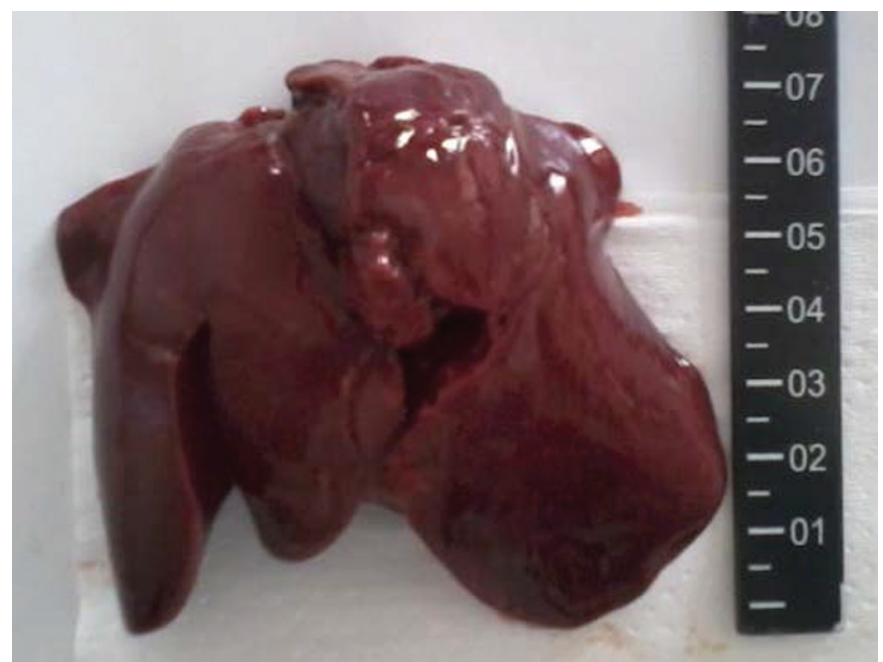

Fig.3. Fígado de ave infectada por Borrelia anserina apresentando hepatomegalia, congestão, superfície irregular e com fissuras (friável).

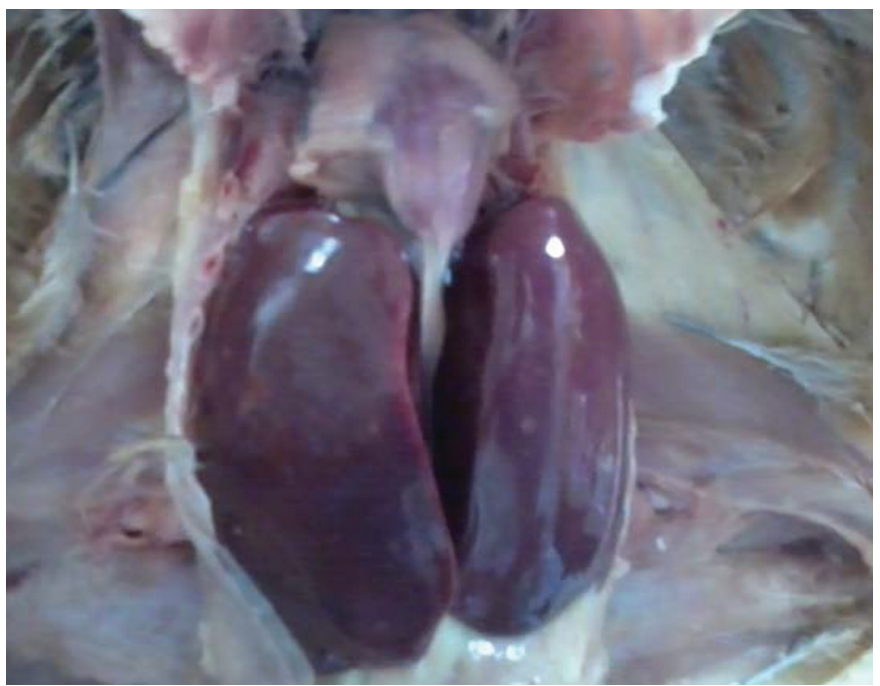

Fig.4. Fígado de ave infectada por Borrelia anserina ocupando grande parte da cavidade celomática, de coloração vermelha a cianótica e com pequenos pontos esbranquiçados na superfície.

ficativa a partir do 3 o dia, com maiores valores na terceira semana. No Grupo 3 infectado houve um pequeno aumento entre $8^{\circ}$ e $12^{\circ}$ DPI, e uma queda após esse período com uma posterior normalização.

Os valores elevados das transaminases nos grupos infectados, nos períodos citados acima, podem ter sido ocasionados pelas lesões hepáticas, com possível diminuição da função do órgão, assim como Capitelli \& Crosta (2013), que relataram que o aumento nos valores dessas enzimas no sangue podem mensurar o grau de lesão hepática. Esse aumento dos níveis séricos das transaminases também pode ser explicado por Kaneko (1989), o qual relata que o distúrbio hepático decorrente do rompimento dos hepatócitos é resultante de alterações na permeabilidade celular.

Segundo Fudge (2000), a enzima ALT não é hepatoespecífica e também indica lesões em outros tecidos. Um aumento desta enzima pode apontar lesões severas do fígado e na musculatura esquelética, embora AST também não seja específica para indicar danos hepáticos nas aves; essa enzima é a mais utilizada para essa finalidade devido à sua alta sensibilidade como marcador de lesão.

A atividade sérica de ALT foi mais evidenciada do que a AST, o que sugere que houve graves danos hepáticos. A atividade de ALT se manteve elevada por mais tempo no Grupo 3, possivelmente pela maior patogenicidade e severidade das lesões no fígado, quando as espiroquetas são inoculadas por carrapatos.

0 fígado de uma ave infectada por $B$. anserina sofre um processo inflamatório agudo intenso, aumenta de tamanho e à necropsia pode apresentar focos de necrose (Boero 1967). Após estudar a patologia da espiroquetose aviária em aves de diferentes idades, Nasri et al. (2010) também relataram alterações hepáticas decorrentes da infecção e observaram fígado congesto, grande e friável. De forma semelhante ao observado por estes autores, o presente experimento também revelou no $4^{\circ}$ DPI das aves do Grupo 1, fígados marcados pelas mesmas lesões e no $8^{\circ}$ DPI das aves do Grupo 3 aumento do órgão e fragilidade tecidual. A principal causa da congestão, aumento do fígado e focos de necrose nas aves dos grupos infectados pode estar associada à presença de substâncias tóxicas produzidas pelas bactérias durante o quadro septicêmico causado pela infecção e pelo processo inflamatório intenso na região (Boero 1967, Santos 1974).

Em um estudo realizado por Vashist (2011) foram também observadas alterações de coloração em fígados de galinhas infectadas por B. anserina, os quais apresentaram coloração mais escura do que normalmente é observado para a espécie. Alterações deste tipo também foram encontradas nos fígados das aves do presente estudo, os quais apresentavam uma coloração vermelha a cianótica.

McNeil et al. (1949) observaram ligeiras diferenças nas alterações hepáticas em perus (Meleagris gallopavo), em relação à infecção em galinhas, quando infectados experimentalmente por B. anserina, com o fígado apresentando ocasionalmente algumas petéquias, pequenos abscessos na superfície, aumento de tamanho e áreas de infarto na periferia do órgão, porém não tão evidentes e consistentes como encontrado em galinhas.

Dentre as alterações microscópicas observadas em aves infectadas por B. anserina, foram relatadas presença de células monocitárias e macrófagos no tecido hepático (Boero 1967), infiltração de células mononucleares nos sinusoides e vários graus de necrose (Srinivasan \& Rao 1966, Shommein \& Khogali 1974), infiltrados inflamatórios linfoplasmocitários multifocal e difuso subcapsular nas áreas portais e periportais e no parênquima, proliferação de tecido conjuntivo fibroso no espaço porta, hepatócitos vacuolizados e tumefeitos, hemorragias extensas, congestão e dilatação de sinusoides (Vashist 2011). No presente estudo, todas estas alterações foram também observadas nos fígados acometidos pela infecção, caracterizando o comprometimento significativo do órgão. Edema nos espaços de Disse foi também uma alteração observada nas aves deste estudo, o que de acordo com Boero (1967) origina-se quando é instalado um quadro de pericolangite.

As alterações enzimáticas observadas durante o experi- 

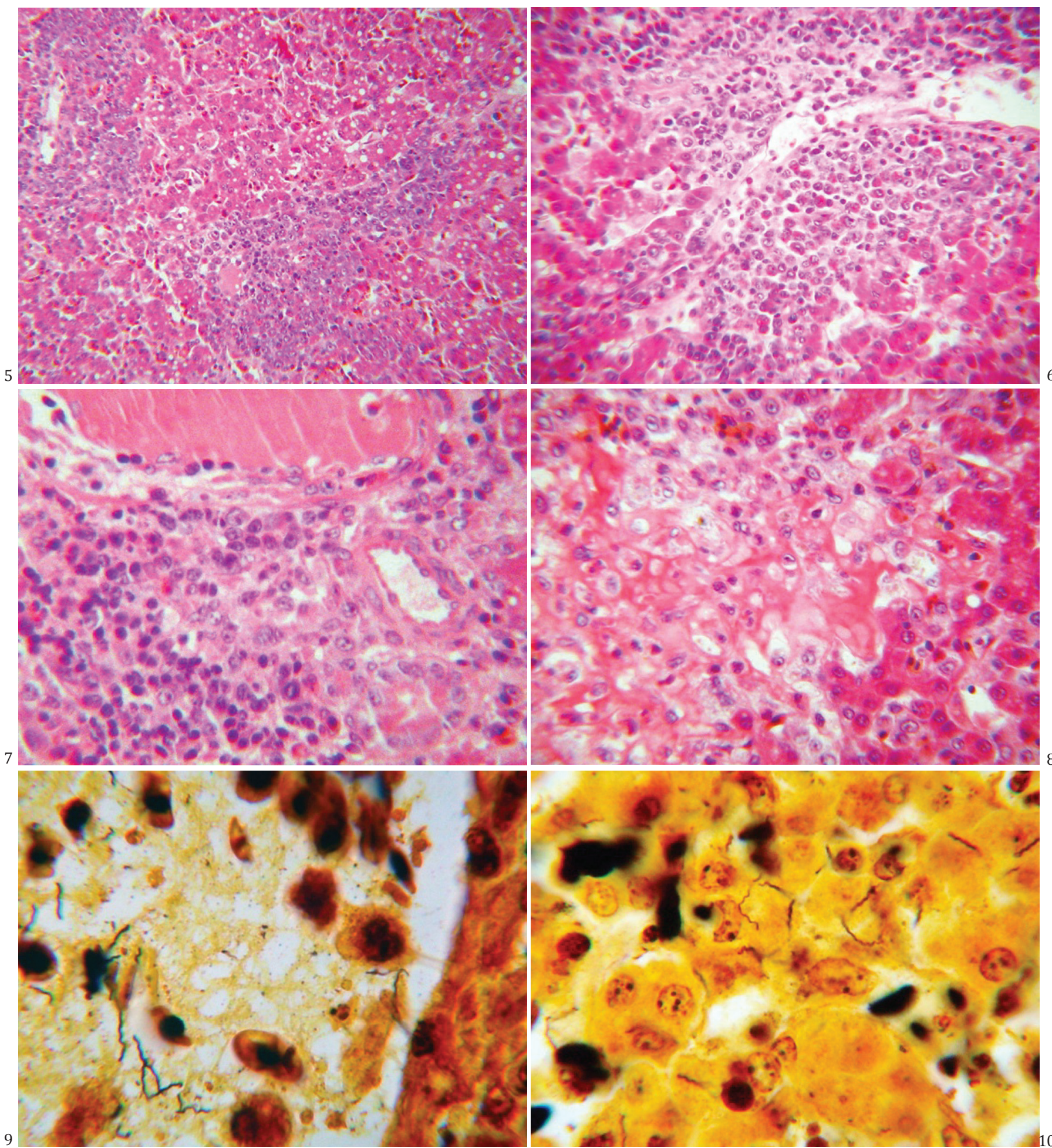

Fig.5. Infiltrado inflamatório mononuclear perivascular e vacuolização difusa leve a moderada de hepatócitos em fígado de ave infectada por Borrelia anserina. HE, obj.6,3x.

Fig.7. Infiltrado inflamatório mononuclear periportal em fígado de ave infectada por Borrelia anserina. HE, obj.40x.

Fig.9. Espiroquetas compatíveis com Borrelia anserina no interior de uma veia centrolobular do fígado de ave do Grupo 3, infectada pelo carrapato (Argas miniatus), eutanasiada no oitavo dia (pico de parasitemia). SAP 32797. Warthin Starry, obj.100x.

Fig.6. Infiltrado inflamatório mononuclear perivascular no fígado de ave infectada por Borrelia anserina. HE, obj.25x.

Fig.8. Foco de necrose fibrinoide em fígado de ave infectada por Borrelia anserina. HE, obj.40x.

Fig.10. Espiroquetas compatíveis com Borrelia anserina no interior de hepatócitos do fígado de ave do Grupo 3, infectada pelo carrapato (Argas miniatus) eutanasiada no oitavo dia (pico de parasitemia). SAP 32797. Warthin Starry, obj.100x. 
mento provavelmente estão associadas aos distúrbios hepáticos causados pela infecção. 0 extravasamento das transaminases ocorre devido à disfunção hepática originada da ruptura dos hepatócitos e também por processos obstrutivos como interrupção do fluxo biliar como comentado por Kaneko (1989).

A impregnação pela prata por meio do método de Whartin-Starry confirmou a presença de espiroquetas nos tecidos hepáticos das aves dos grupos infectados, mais precisamente no interior de veia centrolobular e de hepatócitos, caracterizando desta forma um quadro agudo e septicêmico estabelecido pela doença. Esta técnica de coloração também foi utilizada por Cooper \& Bickford (1993), que observaram uma enorme quantidade de espiroquetas nos vasos sanguíneos e no interstício do fígado, rins e baço de aves infectadas por B. anserina.

\section{CONCLUSÕES}

A infecção por Borellia anserina causou danos hepáticos severos nos grupos de aves infectadas, confirmados através das alterações bioquímicas encontradas, principalmente em relação ao aumento da atividade da enzima ALT.

Estas alterações, associadas aos achados anátomo-histopatológicos no fígado, refletiram fielmente o estado sanitário das aves durante a infecção.

Agradecimentos.- À Professora Cristina Amorim Ribeiro de Lima, Universidade Federal Rural do Rio de Janeiro, pelo auxílio com a formulação e fabricação da ração das aves. À técnica do Laboratório de Histopatologia da UFRRJ, Letícia Baptista Pinto, pelo auxílio e confecção do material de estudo. Aos colegas do Laboratório de Doenças Parasitárias, UFRRJ, pela valiosa ajuda deste trabalho. À Coordenação de Aperfeiçoamento de Pessoal de Nível Superior (CAPES), pela concessão de bolsa de mestrado, e ao Conselho Nacional de Desenvolvimento Científico e Tecnológico (CNPq).

\section{REFERÊNCIAS}

Avila V.S., Albino J. \& Bassi L. 2004. Cuidados Iniciais na Produção do Frango de Corte Colonial Embrapa 041. Embrapa Suínos e Aves, Ministério da Agricultura, Pecuária e Abastecimento. 2p.

Bier O. 1985. Microbiologia e Imunologia. 24a ed. Editora Melhoramentos, São Paulo. 1234p.

Boero J.J. 1967. Parasitosis animales. Editora Universidade de Buenos Aires, Buenos Aires. 498p.

Borsa A., Kohayagawa A., Boretti L.P., Saito M.E. \& Kuibida K. 2006. Níveis séricos de enzimas de função hepática em frangos de corte de criação industrial clinicamente saudáveis. Arq. Bras. Med. Vet. Zootec. 48(4):675-677.

Brasil 2013. Tabela de Agentes e Métodos de Eutanásia para aves por grupos taxonômicos. Diretrizes da Prática de Eutanásia do CONCEA. 43p.

Burgdorfer W. \& Schwan T.G. 1991. Borrelia, 560-566. In: Balows W.J., Hausler J.R., Herrmann K.L., Isenberg H.D. \& Shawdomy H.J. (Eds), Manual of Clinical Microbiology, 5th ed. American Society for Microbiology, Washington, DC.

Capitelli R. \& Crosta L. 2013. Overview of psittacine blood analysis and comparative retrospective study of clinical diagnosis, hematology and blood chemistry in selected psittacine species. Vet. Clin. North Am., Exotic Anim. Pract. 16(1):71-120.

CDPA 2014. Manual de Necropsia. Centro de Diagnóstico e Pesquisa em Patologia Aviária, Universidade Federal do Rio Grande do Sul, Porto Alegre. $14 \mathrm{p}$.

Cooper G.L. \& Bickford A.A. 1993. Spirochetosis in California game chickens. Avian Dis. 37(4):1167-1171.

Cruz F.G.G., Chagas E.O. \& Botelho T.R.P. 2013. Avicultura familiar como al- ternativa de desenvolvimento sustentável em comunidades ribeirinhas do Amazonas. Interações, Campo Grande, 14(2):197-202.

Dickie C.W. \& Barrera J. 1964. A Study of the carrier state of avian spirochetosis in the chicken. Avian Dis. 8(2):191-195.

Fudge A.M. 2000. Avian liver and gastrointestinal testing, p.47-55. In: Fudge A.M. (Ed.), Laboratory Medicine - Avian and Exotic Pets. W.B. Saunders, Philadelphia.

Hoerr F.J. 1996. Liver, p.143-166. In: Ridell C. (Ed.), Avian Histopathol. Library of Congress, Pensylvania.

Hoogstraal H. 1979. Ticks and Spirochetes. Acta Tropica 36:133-136.

Hutyra F., Marek J. \& Manninger R. 1947. Patologia y Terapéutica Especiales de los Animales Domésticos. Vol.1. Editorial Labor, Barcelona. 739p.

Jaensch S. 2000. Diagnosis of avian hepatic disease. Seminars in Avian and Exotic Pet Medicine 9(3):126-135.

Kaneko J.J. 1989. Clinical biochemistry of domestic animals. 4th ed. Academic Press, San Diego. 932p.

Kaneko J.J., Harvey J.W. \& Bruss M.L. 1997. Clinical Biochemistry of Domestic Animals, 5th ed. Academic Press, San Diego. 932p.

Labruna M.B., Resende J.S., Martins N.R.S. \& Jorge M.A. 1999. Cryopreservation of an avian spirochete strain in liquid nitrogen. Arq. Bras. Med. Vet. Zootec. 51(6):551-553.

Levaditi C. \& Lange F. 1905. La spirillose du lapin: mécanisme de la crise. Compt. Rend. Séances Soc. Biol. Ses. Fil, 58:843-845.

Lisbôa R.S. 2006. Estudo da transmissão experimental de Borrelia anserina (Sakharoff, 1891) por Argas (Persicargas) miniatus Kock, 1844 e avaliação comparativa de parâmetros clínicos e hematológicos em Gallus gallus Linnaeus, 1758. Dissertação de Mestrado em Ciências Veterinárias, Universidade Federal Rural do Rio de Janeiro, Seropédica, RJ. 63p.

Lisbôa R.S., Guedes D.S., Silva F.J.M., Cunha N.C., Machado C.H. \& Fonseca A.H. 2008. Alterações nos parâmetros hematológicos de Gallus gallus domesticus experimentalmente infectados por Borrelia anserina. Pesq. Vet. Bras. 28(10):527-532.

Lisbôa R.S., Teixeira R.C., Rangel C.P., Santos H.A., Massard C.L. \& Fonseca A.H. 2009. Avian spirochetosis in chickens following experimental transmission of Borrelia anserina by Argas (Persicargas) miniatus. Avian Dis. 53:166-68.

Marchoux E. \& Salimbeni A. 1903. La spirillose des poules. Annales de l'Institut Pasteur, Lille, 17(1):569-580.

McNeil E., Hinshaw W.R. \& Kissling R.E. 1949. A study of Borrelia anserina infection (spirochetosis) in turkeys. J. Bacteriol. 5(2):191-206.

Nasri I.M.E., Shigidi \& Mohammed M.T.A.M. 2010. Pathology of domestic fowl spirochetosis in different age groups of chicken experimentally infected with Borrelia anserina. Sudan J.Vet. Res. 25:23-28.

Rivetz B., Bogin E., Weisman Y., Avidar J. \& Hadani A. 1977. Changes in the biochemical composition of blood in chickens infected with Borrelia anserina. Avian Pathol. 6:343-351.

Santos J.A. 1974. Patologia geral dos animais domésticos (mamíferos e aves). $2^{\text {a }}$ ed. Interamericana, Rio de Janeiro. 407p.

Shommein A.M. \& Khogali A. 1974. Fowl spirochetosis haematological and histopathological studies. Bull. Epizoot. Dis. Afr. 22(3):255-261.

Souza P.C.A. 1998. Malaria aviária: parasitismo por Plasmodium (Novyella) juxtanucleare Versiani et Gomes, 1941 em Gallus gallus de criações rústicas nas mesorregiões do Estado do Rio de Janeiro e aspectos clínicos e patológicos de sua infecção experimental. Tese de Doutorado em Ciências Veterinárias, Universidade Federal Rural do Rio de Janeiro, Seropédica, RJ. 137p.

Srinivasan V.V. \& Rao S.B.V. 1966. Studies on the histopathology of avian spirochaetosis. Poult. Pathol., Sect. Ind. Vet. Res. Inst. 43(10):916-919.

Vashist U. 2011. Avaliação biológica, bioquímica e histopatológica das infecções experimentais causadas por Plasmodium (Bennettinia) juxtanucleare Versiani \& Gomes, 1941 e Borrelia anserina Sakharoff, $1891 \mathrm{em}$ Gallus gallus Linnaeus, 1758. Tese de Doutorado em Ciências Veterinárias, Universidade Federal Rural do Rio de Janeiro, Seropédica, RJ. 114p.

Wouda W., Veen T.W.S.V. \& Barnes H.J. 1975. Borrelia anserina in chickens previously exposed to Borrelia theileri. Avian Dis. 19(1):209-210. 